\title{
ChemComm
}

\section{Near-IR luminescent neodymium complexes: spectroscopic probes for hydroamination catalysis $\uparrow$}

Cite this: Chem. Commun., 2013, 49, 6072

Received 19th April 2013,

Accepted 24th May 2013

DOI: $10.1039 / c 3 c c 42923 g$

www.rsc.org/chemcomm

Neodymium complexes bearing the sensitising bis(oxazolinylphenyl)amine (BOPA) ligands have been prepared, and analysed spectroscopically under both catalytic and pseudo-catalytic conditions with respect to the intramolecular hydroamination of an aminoalkene, providing a direct means of monitoring binding events and relative space around the metal centre.

Rare-earth metal complexes have many applications in catalysis, including hydroamination. ${ }^{1}$ The presence of partially occupied, lowlying $4 \mathrm{f}$ orbitals also gives them unique spectroscopic properties. The formally forbidden $\mathrm{f}-\mathrm{f}$ transitions are notably sharp compared to many other fluorescence systems, and the long near-IR wavelength provides an emission profile that is largely free from environmentally emissive 'pollution'. 2

The spectroscopic fingerprint of a luminescent lanthanide ion (i.e. spectral profile and lifetime of f-centred emission) is uniquely sensitive to the local coordination environment. ${ }^{3}$ In particular, the lifetime provides information on the relative shielding of the ion from bound and unbound proximate quenchers, such as $\mathrm{O}-\mathrm{H}, \mathrm{N}-\mathrm{H}$ and $\mathrm{C}-\mathrm{H}$ oscillators, ${ }^{4}$ present in solvents, (bound) substrates, ligand architectures, and/or the proximity of stereodirecting groups. This parameter may therefore provide reportage on the space at the metal centre in which catalytic reactions take place, and may provide critical information relating to the short-lived species that lie beyond the detection limit of many other analytical techniques. ${ }^{5}$

Our goal in this study was to use the luminescent properties of $\mathrm{Nd}$ (III) to probe the intricate nature of chiral complexes, providing information that cannot be obtained using other spectroscopic techniques, and to relate this information to their behaviour in hydroamination/cyclisation catalysis.

The bis(oxazolinylphenyl)amine (BOPA) series of ligands ${ }^{6}$ are able to efficiently sensitise the metal-centred excited states of neodymium,

School of Chemistry, Cardiff University, Main Building, Park Place, Cardiff CF10 3AT, UK. E-mail: WardBD@Cardiff.ac.uk; Fax: +44 (0)29 208 74030; Tel: +44 (0)29208 70302

$\dagger$ Electronic supplementary information (ESI) available: Full experimental procedures, crystal, computational and characterising data for all new complexes. CCDC 903609. For ESI and crystallographic data in CIF or other electronic format see DOI: $10.1039 / \mathrm{c} 3 \mathrm{cc} 42923 \mathrm{~g}$

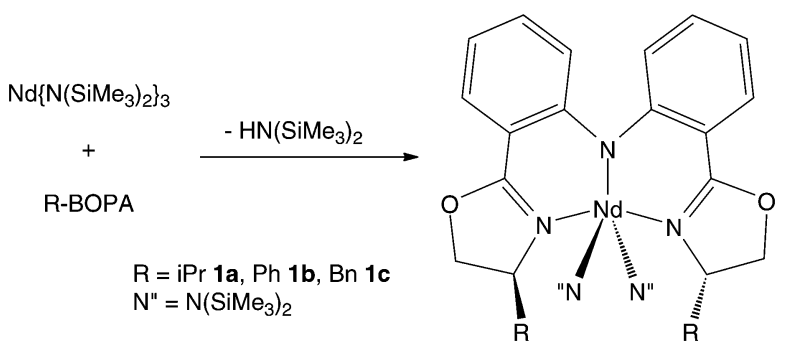

Scheme 1 Preparation of $\left[\mathrm{Nd}(\mathrm{R}-\mathrm{BOPA})\left\{\mathrm{N}\left(\mathrm{SiMe}_{3}\right)_{2}\right\}_{2}\right]$ 1a-c.

such that the resultant near-IR photophysical properties can be used to probe the complexes under conditions relevant to catalytic reactions. In their anionic form, these ligands possess conjugated amides coordinated to the lanthanide in an ideal position to aid investigations in to the luminescence properties of the species.

The protio-ligands react with the neodymium precursor $\left[\mathrm{Nd}\left\{\mathrm{N}\left(\mathrm{SiMe}_{3}\right)_{2}\right\}_{3}\right]$ to afford the five-coordinate complexes $\left[\mathrm{Nd}(\mathrm{R}-\mathrm{BOPA})\left\{\mathrm{N}\left(\mathrm{SiMe}_{3}\right)_{2}\right\}_{2}\right](\mathrm{R}=\mathrm{iPr}$ 1a, Ph 1b, Bn 1c) (Scheme 1). The ${ }^{1} \mathrm{H}$ NMR data of the paramagnetic complexes were found to give relatively sharp signals with an expected reduction in fine structure and an increase in chemical shift range (ca. 20 to $-40 \mathrm{ppm}){ }^{7}$ The overall molecular symmetry, number of resonances, and their relative intensity are fully consistent with the proposed structures. The resonance attributed to the two equivalent $\mathrm{N}\left(\mathrm{SiMe}_{3}\right)_{2}$ ligands is a distinctive, large singlet in the range of -5.96 to $-5.93 \mathrm{ppm}$. The structure of $\left[\mathrm{Nd}(\mathrm{Ph}-\mathrm{BOPA})\left\{\mathrm{N}\left(\mathrm{SiMe}_{3}\right)_{2}\right\}_{2}\right]$ 1b has been confirmed by X-ray crystallography; X-ray data are included in the ESI. $\dagger^{8}$

Complexes 1a-c were employed in the catalytic hydroamination of aminoalkenes (vide infra). The catalyst resting state for this reaction (i.e. a tethered amidoalkene) is well understood, ${ }^{9}$ but cannot be isolated owing to the intramolecular nature of the reaction. Therefore model complexes were prepared that suppress the catalytic turnover by removing the $\mathrm{C}=\mathrm{C}$ from the substrate. The resulting complexes were prepared using the pseudo substrate 2,2'-diphenyl-aminopentane, to afford [Nd(R-BOPA $\left.)\left\{\mathrm{NHCH}_{2} \mathrm{C}\left(\mathrm{Ph}_{2}\right) \operatorname{Pr}\right\}_{2}\right](\mathrm{R}=\mathrm{iPr} \mathbf{2 a}, \mathrm{Ph} 2 \mathbf{b}, \mathrm{Bn} 2 \mathbf{c})$ according to Scheme 2 . The ${ }^{1} \mathrm{H}$ NMR data of complexes $3 \mathrm{a}-\mathrm{c}$ showed similar features to the spectra of $1 \mathbf{a}-\mathbf{c}$ in terms of the overall $C_{2}$ symmetry of the complexes. In comparison to the data obtained for 

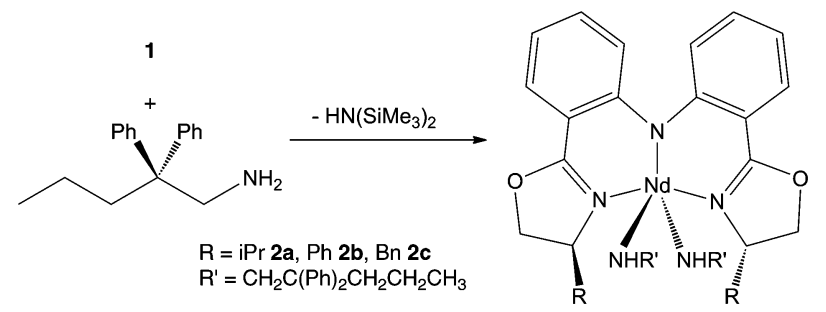

Scheme 2 Preparation of $\left.\left[\mathrm{Nd}(\mathrm{R}-\mathrm{BOPA})\left\{\mathrm{NHCH}_{2} \mathrm{C}(\mathrm{Ph})_{2} \mathrm{Pr}\right)\right\}_{2}\right] 2 \mathrm{a}-\mathrm{c}$.

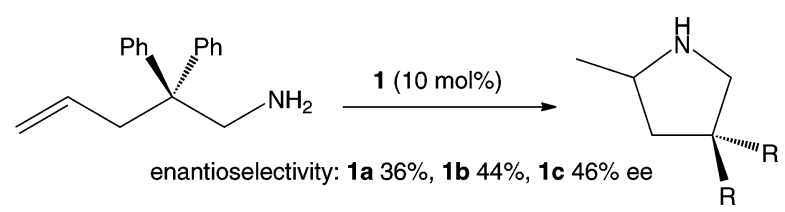

Scheme 3 Catalytic hydroamination using $\left[\mathrm{Nd}(\mathrm{R}-\mathrm{BOPA})\left\{\mathrm{N}\left(\mathrm{SiMe}_{3}\right)_{2}\right\}_{2}\right]$.

complexes 1a-c the signal assigned to the silylamide co-ligands was absent from the spectra of $2 \mathbf{a}-\mathbf{c}$.

The spectroscopic analysis of these complexes can only provide adequate information relating to their catalytic performance if supported by a clear demonstration of their implementation in the catalytic reaction being studied. Consequently, complexes 1a-c were employed in the hydroamination/cyclisation of 2,2'-diphenyl-amino-pent-4-ene in toluene- $\mathrm{d}_{8}$ using $10 \mathrm{~mol} \%$ catalyst at $25{ }^{\circ} \mathrm{C}$ (Scheme 3$)^{10}$ All reactions proceeded to quantitative conversion and with moderate enantioselectivities. The phenyl and benzyl derivatives $\mathbf{1 b}$ and $\mathbf{1 c}$ gave essentially identical enantiomeric excesses of $44-46 \%$, whereas the isopropyl congener 1a gave a lower level of selectivity (36\%). These moderate levels of selectivity can be reasonably explained by the presence of two isomeric forms of the complexes (which the luminescence studies would suggest pertain during the catalytic reaction and that have been identified computationally, vide infra), particularly where one of the components moves the stereodirecting groups away from the expected site of alkene insertion.

Solutions of 1a-c (toluene, $10^{-4} \mathrm{M}, \mathrm{N}_{2}$ atmosphere) were investigated from a photophysical standpoint and are described as dual emissive. Irradiation $\left(\lambda_{\text {ex }}=485 \mathrm{~nm}\right)$ induced visible emission from the complexes, typically characterised by a broad, unstructured luminescence band peaking between $500-510 \mathrm{~nm}$ with a small associated Stokes' shift $\left(c a .1000 \mathrm{~cm}^{-1}\right) \cdot{ }^{11}$ The precise positioning of the band and the fluorescence lifetime (5.0, 4.6 and $4.5 \mathrm{~ns}$, for $\mathrm{R}={ }^{\mathrm{i}} \mathrm{Pr}$, $\mathrm{Ph}$ and $\mathrm{Bn}$ respectively) were subtly dependent on the specific composition of the ligand. The diphenylamine anion is known to be non-emissive, ${ }^{12}$ and therefore the visible fluorescence was attributed to a ligand-centred excited state with a contributing charge transfer ( $\mathrm{N}$-to- $\pi^{*}$ ) component originating from the deprotonated/coordinated amide bridge-head.

Irradiation of solutions 1a-c at $445 \mathrm{~nm}$ also induced sensitised near-IR emission from each of the $\mathrm{Nd}(\mathrm{III})$ complexes, with characteristic bands attributed to the ${ }^{4} \mathrm{~F}_{3 / 2}{ }^{4} \mathrm{I}_{9 / 2},{ }^{4} \mathrm{~F}_{3 / 2}-{ }^{4} \mathrm{I}_{11 / 2}$ and ${ }^{4} \mathrm{~F}_{3 / 2}-{ }^{4} \mathrm{I}_{13 / 2}$ transitions. The corresponding lifetime measurements were also obtained $\left(\lambda_{\mathrm{em}}=1055 \mathrm{~nm}\right)$ and are shown in Table 1; the magnitude of the values are consistent with $\mathrm{Nd}(\mathrm{III})$-centred emission, and each profile fitted reasonably well to a bi-exponential decay yielding two distinct lifetime values. These data suggest that each of the
Table 1 Lifetime measurements for $\left[\mathrm{Nd}(\mathrm{R}-\mathrm{BOPA})\left\{\mathrm{N}\left(\mathrm{SiMe}_{3}\right)_{2}\right\}_{2}\right]$ and related complexes (toluene, $\mathrm{N}_{2} ; \lambda_{\mathrm{ex}}=355 \mathrm{~nm} ; \lambda_{\mathrm{em}}=1055 \mathrm{~nm}$ )

\begin{tabular}{llll}
\hline & Lifetimes $(\tau) / \mathrm{ns}$ & \\
\cline { 2 - 4 } Compound & & $\begin{array}{l}\text { +2,2-Diphenyl- } \\
\text { aminopentane }\end{array}$ & $\begin{array}{l}\text { +2,2-Diphenyl- } \\
\text { aminopentene }\end{array}$ \\
\hline 1a & $148,621(70 \%)$ & $111,267(59 \%)(2 a)$ & - \\
1b & $129,677(90 \%)$ & $71,165(90 \%)(2 b)$ & - \\
1c & $41,308(80 \%)$ & $41,182(93 \%)(2 c)$ & $81,252(85 \%)$ \\
\hline
\end{tabular}

complexes $\left[\mathrm{Nd}(\mathrm{R}-\mathrm{BOPA})\left\{\left(\mathrm{N}\left(\mathrm{SiMe}_{3}\right)_{2}\right\}_{2}\right]\right.$ (1a-c) exists in (at least) two distinct environments. The fact that the analytical and NMR data suggest a single pure complex suggests that these species are likely to be interconverting isomers.

The lifetimes of the two species are remarkably different, and suggest that the main component represents a well-shielded $\mathrm{Nd}$ (III) centre, possibly representative of the X-ray structure. The second component (10-30\% relative weighting) has a significantly shorter lifetime and suggests a species that is more readily quenched (i.e. by proximate $\mathrm{C}-\mathrm{H}$ oscillators), possibly arising from a ligand conformation that renders the metal more accessible to solvent molecules. The lifetimes for the isopropyl and phenyl derivatives $\mathbf{1 a}$ and $\mathbf{1 b}$ are similar, suggesting a comparable environment around the $\mathrm{Nd}(\mathrm{III})$ centre, whereas the lifetimes for the benzyl derivative $1 \mathrm{c}$ are shorter, implying less effective shielding. This may originate in the greater flexibility of a benzyl (at the methylene group) relative to phenyl and isopropyl groups, which are generally more rigid.

Importantly, the relative intensity of the emission bands of $\mathrm{Nd}(\mathrm{m})$ are known to be sensitive to the local coordination environment, 3,13 suggesting that changes in either ligand type or ligand arrangement will modulate the emission profile of a luminescent $\mathrm{Nd}(\mathrm{II})$ complex. In this context, addition of the saturated pseudo-substrate $\left(2,2^{\prime}\right.$-diphenylaminopentane) to form $2 \mathbf{a}-\mathbf{c}$, subsequently showed a definitive and measurable change in spectral emission profile (in terms of peak position, profile and integrated intensity, Fig. 1), as well as significant alterations in $\mathrm{Nd}(\mathrm{II})$ lifetime. Such observations are clearly indicative of changes in the coordination environment and thus consistent with the bis(trimethylsilyl)amide ligands exchanging with the $2,2^{\prime}$-diphenylamino-pentane ligands, establishing that coordination to the $\mathrm{Nd}(\mathrm{mI})$ must occur via the terminal amino group of the pseudo-substrate. The dominant lifetime components for $\mathbf{2 a - c}$ are significantly shortened compared to 1a-c and consistent with a ligand substitution that would introduce $\mathrm{N}-\mathrm{H}$ oscillators into the coordination sphere and reduce the steric crowding at $\mathrm{Nd}(\mathrm{III})$.

During the catalytic hydroamination reaction, the proposed cyclised intermediate is coordinated to $\mathrm{Nd}(\mathrm{II})$ via a methylene unit. ${ }^{9}$ Therefore the actual catalytic substrate, 2,2'-diphenyl-amino-pent-4ene, was also used with $2 \mathbf{c}$ and, again, revealed modulation of the emission profile and shortening of the dominant lifetime component to $252 \mathrm{~ns}$. Again, these observations are consistent with a substrate binding event, but one that is distinct from the pseudosubstrate. The lifetime data for this mixture can therefore be differentiated from both the free complex (1c) and the speciation of the saturated substrate analogue (2c).

The identity of the two components of $2 \mathbf{a}-\mathbf{c}$ (and by extension 1a-c) was probed by calculating the structures of the $\mathbf{L a}(\mathrm{III})$ congeners; the structures of $\mathbf{L a}-\mathbf{2} \mathbf{b}$ are shown in Fig. 2. 


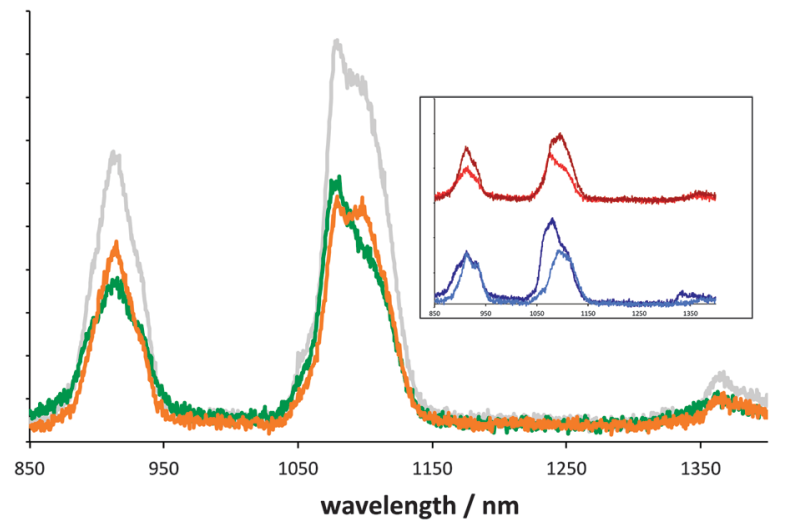

Fig. 1 Near-IR luminescence spectra $\left(10^{-4} \mathrm{M}\right.$ toluene, $\left.\lambda_{\mathrm{ex}} 445 \mathrm{~nm}\right)$. Main: 1c (green), 2c (orange), 1c $+2,2^{\prime}$-diphenyl-amino-pentene (grey). Inset: comparison 1a/2a (light blue/dark blue) and $1 \mathrm{~b} / 2 \mathrm{~b}$ (red/brown).

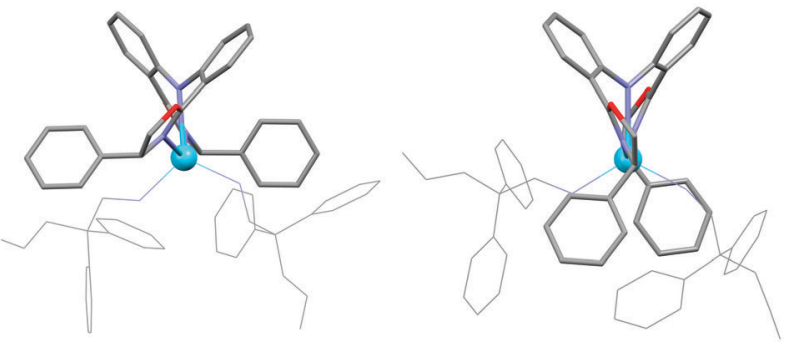

Fig. 2 Calculated exo (left) and endo (right) isomers of La-2b

Calculations suggest that each of the complexes exist in two energetically accessible forms, each with a different sense of helical twist in the diphenyl backbone of the BOPA ligands, giving both exo and endo isomers with respect to the orientation of the stereodirecting groups. The exo isomer is consistent with the X-ray data, and is computationally favoured. It can be seen from Fig. 2 that the metal centre in the endo isomer is significantly less shielded than the exo isomer, and would therefore be more accessible to solvent molecules, accounting for the observed difference in the lifetimes of the two components. Additionally, the relative steric encumbrance of the stereodirecting group is evident, showing that the isopropyl offers the least steric demand and therefore is expected to give less energetic distinction between the isomeric forms, as observed experimentally by luminescence spectroscopy (Table 1).

The exo isomer of a given ligand derivative places the stereodirecting groups in the equatorial plane of the coordination sphere, shielding the metal centre to a greater extent than the endo isomer, which possesses a significant space that is largely unaffected by the ligand periphery (i.e. stereodirecting group). The exo isomer therefore possesses a better-defined chiral space at the coordination sphere, and is more likely to efficiently transfer chiral information to the catalytic substrates. We propose therefore that the relative proportion of these isomers is likely to be a significant contributor to the effectiveness of these complexes to evoke stereoselectivity in catalysis. The experimental data, showing that a higher proportion of the exo isomer is found for the catalyst that generates the highest enantiomeric excess, supports this theory; however this does not contradict the effects of varying the size of the stereodirecting group. Rather, these studies show evidence of additional processes taking place at the molecular level that contribute to the overall effect of controlling stereoselectivity in catalysis.

The photophysics of luminescent neodymium complexes have been used to directly probe the metal species in the catalytic system, with emission profiles before, during, and after giving distinct luminescence signatures. The luminescence studies indicate the presence of different conformations of the complex in solution that are not apparent using NMR spectroscopy and X-ray crystallography. We propose that the presence of these conformations is a key aspect for explaining the relative stereocontrol offered by the different catalyst derivatives.

We thank Cardiff University (Endowment Fellowship to SDB and access to computing facilities "ARCCA"), the Leverhulme Trust, and the EPSRC crystallographic service for support.

\section{Notes and references}

1 (a) B. D. Ward and L. H. Gade, Chem. Commun., 2012, 48, 10587; (b) S. Hong and T. J. Marks, Acc. Chem. Res., 2004, 37, 673; (c) G. A. Molander and J. A. C. Romero, Chem. Rev., 2002, 102, 2161; (d) Z. Hou and Y. Wakatsuki, Coord. Chem. Rev., 2002, 231, 1.

2 J.-C. G. Bünzli and S. V. Eliseeva, Chem. Sci., 2013, 4, 1939.

3 (a) J.-C. G. Bünzli, A.-S. Chauvin, H. K. Kim, E. Dieters and S. V. Eliseeva, Coord. Chem. Rev., 2010, 254, 2623; (b) S. Faulkner, S. J. A. Pope and B. P. Burton-Pye, Appl. Spectrosc. Rev., 2005, 40, 1. 4 (a) W. D. Horrocks Jr. and D. R. Sudnick, Acc. Chem. Res., 1981, 14, 384; (b) E. G. Moore, A. P. S. Samuel and K. N. Raymond, Acc. Chem. Res., 2009, 42, 542; (c) A. Beeby, I. M. Clarkson, R. S. Dickins, S. Faulkner, D. Parker, L. Royle, A. S. de Sousa, J. A. G. Williams and M. Woods, J. Chem. Soc., Perkin Trans. 2, 1999, 493.

5 (a) X. Zhu, W.-K. Wong, W.-Y. Wong and X. Yang, Eur. J. Inorg. Chem., 2011, 4651; (b) B. K. McMahon and T. Gunnlaugsson, J. Am. Chem. Soc., 2012, 134, 10725; (c) W. Chen, B. D. Wright and Y. Pang, Chem. Commun., 2012, 48, 3824.

6 (a) H. A. McManus and P. J. Guiry, J. Org. Chem., 2002, 67, 8566; (b) S.-F. Lu, D.-M. Du, S.-W. Zhang and J. Xu, Tetrahedron: Asymmetry, 2004, 15, 3433; (c) H. A. McManus, P. G. Cozzi and P. J. Guiry, Adv. Synth. Catal., 2006, 348, 551; (d) T. Inagaki, L. T. Phong, A. Furuta, J.-I. Ito and H. Nishiyama, Chem.-Eur. J., 2010, 16, 3090.

7 (a) L. Lukešová, B. D. Ward, S. Bellemin-Laponnaz, H. Wadepohl and L. H. Gade, Dalton Trans., 2007, 920; (b) L. Lukešová, B. D. Ward, S. Bellemin-Laponnaz, H. Wadepohl and L. H. Gade, Organometallics, 2007, 26, 4652.

8 X-ray data were collected by the EPSRC National Crystallographic Service: S. J. Coles and P. A. Gale, Chem. Sci., 2012, 3, 683.

9 (a) M. R. Gagnè, C. L. Stern and T. J. Marks, J. Am. Chem. Soc., 1992, 114, 275; (b) Y. Li and T. J. Marks, J. Am. Chem. Soc., 1996, 118, 9295; (c) A. Motta, G. Lanza, I. L. Fragalà and T. J. Marks, Organometallics, 2004, 23, 4097.

10 For selected examples of asymmetric hydroamination catalysis using lanthanides see: (a) Y. Li and T. J. Marks, Acc. Chem. Res., 2004, 37, 673; (b) S. Hong, S. Tian, M. V. Metz and T. J. Marks, J. Am. Chem. Soc., 2003, 125, 14768; (c) P. N. O'Shaughnessy and P. Scott, Tetrahedron: Asymmetry, 2003, 14, 1979; (d) P. N. O'Shaughnessy, P. D. Knight, C. Morton, K. M. Gillespie and P. Scott, Chem. Commun., 2003, 1770; (e) P. N. O’Shaughnessy, K. M. Gillespie, P. D. Knight, I. J. Munslow and P. Scott, Dalton Trans., 2004, 2251.

11 For a comprehensive and authoritative review of issues relating to fluorescence see J. R. Lakowitz, Principles of Fluorescence Spectroscopy, Springer, New York, third edn, 2006.

12 N. Chattopadhyay, A. Samanta, T. Kundu and M. Chowdhury, J. Photochem. Photobiol., A, 1989, 48, 61.

13 S. J. A. Pope, B. P. Burton-Pye, R. Berridge, T. Khan, P. J. Skabara and S. Faulkner, Dalton Trans., 2006, 2907. 